\title{
Open-Ended Versus Closed-Ended Responses: A Comparison Study Using Topic Modeling and Factor Analysis
}

\author{
Baburajan, Vishnu; de Abreu e Silva, Joao; Pereira, Francisco Camara
}

Published in:

IEEE Transactions on Intelligent Transportation Systems

Link to article, DOI:

10.1109/TITS.2020.3040904

Publication date:

2021

Document Version

Peer reviewed version

Link back to DTU Orbit

Citation (APA):

Baburajan, V., de Abreu e Silva, J., \& Pereira, F. C. (2021). Open-Ended Versus Closed-Ended Responses: A Comparison Study Using Topic Modeling and Factor Analysis. IEEE Transactions on Intelligent Transportation Systems, 22(4), 2123 - 2132. https://doi.org/10.1109/TITS.2020.3040904

\section{General rights}

Copyright and moral rights for the publications made accessible in the public portal are retained by the authors and/or other copyright owners and it is a condition of accessing publications that users recognise and abide by the legal requirements associated with these rights.

- Users may download and print one copy of any publication from the public portal for the purpose of private study or research.

- You may not further distribute the material or use it for any profit-making activity or commercial gain

- You may freely distribute the URL identifying the publication in the public portal 


\title{
Open-Ended Versus Closed-Ended Responses: A Comparison Study Using Topic Modeling and Factor Analysis
}

\author{
Vishnu Baburajan ${ }^{(}$, João de Abreu e Silva, and Francisco Camara Pereira ${ }^{\circledR}$, Member, IEEE
}

\begin{abstract}
For practical reasons, surveys that aim for a large number of respondents tend to restrict themselves to closed-ended responses. Despite potentially bringing richer insights, the use of open-ended questions poses great challenges in terms of extracting useful information while significantly increasing the analysis time. Nevertheless, automatic text analysis techniques speed up the analysis of open-ended responses. In this research, we explore the potential to use techniques in topic modelling [Latent Dirichlet Allocation (LDA) and Supervised LDA (sLDA)] to extract information from open-ended responses. This is compared to the information obtained from closed-ended responses, accomplished using a questionnaire that measures the intention to use shared autonomous vehicles (SAVs). Two versions of the questionnaire- Ver_OE and Ver_Lk were used, with open-ended and Likert scales measuring the same attitudes in the alternative versions. Factors were extracted for closed-ended questions. For questions common to both versions of the questionnaire, respondents answering Ver_OE had a higher positive attitude towards autonomous vehicles. These attitudinal questions were placed after the open-ended questions. When evaluating the performance of the models that predict the intention to use SAVs, models estimated using Ver_OE performed better. This increased further with the inclusion of the information extracted from the open-ended responses using both, the unsupervised (LDA) and supervised (sLDA) methods. No improvement was observed in the model for Ver_Lk. These indicate the potential for the use of open-ended questions to measure attitudes and topic modelling to extract information from these responses.
\end{abstract}

Index Terms-Topic modelling, latent dirichlet allocation, supervised latent dirichlet allocation, Likert scales, open-ended questions, travel behaviour research.

\section{INTRODUCTION AND BACKGROUND}

A TTITUDES are psychological constructs characterising an individual. They are qualitative and are important for

Manuscript received May 21, 2020; revised November 4, 2020; accepted November 11, 2020. This work was supported in part by the Short-Term Scientific Mission from COST Action TU1305 of the European Cooperation for Science and Technology and by the Fundação para a Ciência e a Tecnologia (FCT, IP), Portugal, under the grant number PD/BD/129394/2017. The Associate Editor for this article was T. Galvão Dias. (Corresponding author: Vishnu Baburajan.)

Vishnu Baburajan is with the Department of Civil Engineering, Architecture and Georesources, Instituto Superior Técnico, 1049-001 Lisbon, Portugal, and also with the Management Engineering Department, Technical University of Denmark, 2800 Lyngby, Denmark (e-mail: vishnu.baburajan@tecnico.ulisboa.pt).

João de Abreu e Silva is with the Department of Civil Engineering, Architecture and Georesources, Instituto Superior Técnico, 1049-001 Lisbon, Portugal (e-mail: jabreu@tecnico.ulisboa.pt).

Francisco Camara Pereira is with the Management Engineering Department, Technical University of Denmark, 2800 Lyngby, Denmark (e-mail: camara@dtu.dk).

Digital Object Identifier 10.1109/TITS.2020.3040904 both researchers and policymakers alike. They have profound applications in multiple fields, particularly in psychology [1], [2] and politics [3]-[6]. In the field of transportation, they have been used to analyse the intention to use a new service [7], [8], attitudes towards services [9], traveller preferences [10], and attitudes towards driving behaviour [11], [12], to mention a few.

To measure the attitudes towards AVs we could use closedended question such as, "Your opinion on AVs on a rating scale of 1-5 is ..." or an open-ended question "Tell us your opinion about AVs". However, are closed-ended or open-ended responses better suited for measuring latent construct? This research question has drawn significant attention among researchers from different disciplines. The balance has however shifted mostly in favour of the use of closed-ended responses mainly due to the very fast operation for closed-ended surveys [13] and higher completion and execution time for open-ended surveys [14].

When the closed-ended approach is used, individuals are presented with statements describing the attitude being measured. Individuals interpret the question, understand the attitude being measured, and retrieve the relevant beliefs and feelings. The individual then applies these to arrive at an appropriate judgement before selecting the point on the scale that best describes the attitude [15]. Bipolar scales are based on the notion that attitudes are bipolar constructs ranging between the two extremes. Unipolar scales measure the amount of importance of an attitude to an individual [16]. The simplicity in use, easiness in administering and coding has contributed to the widespread use of closed-ended approach [17]. However, it does suffer from some drawbacks. The analyst must make careful decisions regarding the length, the inclusion of midpoint, labelling, etc. before using a scale [16]. The optimal number of points on a scale has been a subject of intense debate with researchers arguing in favour of 5- and 7-points scales [18], [19], a debate that has yet not reached a consensus [20], [21]. Researchers use several types of scales, often ranging from 3- to 7-points to measure attitudes [9], [11], [22]-[24]. Another challenge associated with the use of closedended responses is if neutral points (middle point) should be included or not. Scales without neutral point prevent respondents from choosing the middle option [17] and reduce social desirability bias [25]. This may, however, force individuals who are neutral to agree or disagree, eventually making it impossible to capture their attitudes [26]. Furthermore, they suffer from acquiescence by endorsing statements to satisfy 
enumerators [17]. In online surveys, respondents can be more sensitive to scales [27] and the visual presentation (horizontal $\mathrm{v} / \mathrm{s}$ vertical) of scales can have implications on the responses [28]. Despite these, closed-ended responses have been and continue to be widely used in research.

On the other hand, open-ended approaches encourage individuals to formulate their thoughts and articulate the same in words. Open-ended questions perform better at measuring knowledge and produce more reliable and valid information [29]. They are effective in capturing attitudes about issues that are relatively complicated and new, or that might garner very little attention or even issues about which people may not have thought extensively [30]. They can also be used to measure the frequency of undesirable behaviour such as smoking, alcohol consumption, etc., [17]. Compared to the closed-ended, openended increases the burden of the respondents, enumerators and analysts [31]. Some researchers argue that they measure the ability of the respondent to articulate a response and not the attitude [32]. The space for open-ended responses, clearly stated instructions [33] and respondent's interest [6], [34], could affect response length and quality of information. Item non-response [34], ambiguity in responses [14], survey break-off [35] are some of the other issues associated with the use of open-ended questions. These aspects have deterred the widespread use of open-ended responses to measure attitudes.

Recent advances in Topic Modelling open up possibilities for the extraction of information from text. They have been previously used in the prediction of nonhabitual overcrowding of public transport [36] and taxi demand [37] based on information on the special events on the internet, travel route recommendations using geotagged photos [38], [39] and discover trip patterns such as destination, time of arrival, day of the week and stay duration using data from transit smart card records [40]. In addition to this, Zhao et al. [40] also distinguishes between home, work and other activities, whereas Wang et al. [41] focussed only on the identification of trip purpose for public transportation trips. Hasan and Ukkusuri [42] used the information shared on social media platforms to obtain multi-day activity patterns of individuals.

To extract information from the open-ended responses from the American National Election Study (ANES), Roberts et al. [43] used structured topic models. Topic modelling was used to extract information from open-ended responses in the context of market research. This reduced the analysis time and human bias, but the accuracy of predictions was affected by the frequency of topics. Furthermore, the number of topics could adversely affect the quality of the topics [44]. Tvinnereim and Fløttum [45] and Mitsui et al. [46] used topic modelling to extract information from the open-ended survey questions related to climate change and protected area assessment respectively. We could not find the application of topic models to extract information from open-ended responses in the context of travel behaviour research. If found beneficial, policymakers and analysts could use these techniques to extract information from open-ended responses in travel behaviour research.
We investigate the potential for the use of topic models to extract information on attitudes from open-ended responses and to quantify the improvements with its use. We use as a case study the intention to use Shared Autonomous Vehicles (SAVs). To measure the attitudes towards SAVs we could use closed-ended question such as, "Your opinion on SAVs on a rating scale of 1-5 is ..." or an open-ended question "Tell us your opinion about SAVs". Two versions of the same questionnaire are used, with one version using open-ended questions to collect information on some of the attitudes and the other using only Likert scale questions.

To understand the potential for the use of open-ended responses to measure attitudes, we extract variables from open-ended questions using the Latent Dirichlet Allocation (LDA) and supervised Latent Dirichlet Allocation (sLDA). They are then used to estimate models to predict the intention to use Shared Autonomous Vehicles (SAVs). Variables describing attitudes, subjective norms, and perceived behavioural control are also included in the model. The goodness-of-fit of these models is used to quantify improvements with the use of open-ended responses.

This paper comprises five sections. The following section describes the questionnaire design and the data collection. The third section describes the data. A detailed discussion of the methodology is presented in the fourth section. The results of the model estimation are presented in the fifth sections. The last section summarises the findings of our research and discusses the directions for future research.

\section{Questionnaire Design And Data Collection}

To design the questionnaire, we used the Theory of Planned Behaviour (TPB) [47]- widely used in travel behaviour research [7], [9]. TPB posits that attitudes, along with subjective norms and perceived behavioural control shape an individual's behavioural intention and eventually behaviour. To identify the attitudes, we identified the factors that influence the intention to use Autonomous Vehicles (AVs). We use these, along with the attitudes influencing the use of public transportation to measure the intention to use SAVs. It depends on the technological savviness, environmental consciousness [48], socio-demographic characteristics and familiarity with the advances in vehicle technology [49]. Attitudes about AVs were based on the perceptions about its effect on road safety [50]. Individual's perception of improvements to transportation system efficiency with the use of AVs, through congestion mitigation, better transport and parking operations; reduced fuel consumption; while ensuring mobility for all is likely to influence their use [51], [52]. The concerns regarding their use are often linked to pricing and licensing of vehicles, litigation and liabilities during accidents, security threats due to hacking and system failures, and privacy [51], [53]. A comprehensive review of the recent developments in the literature on AVs, in terms of the frameworks used for measuring perceptions and the potential benefits and impacts, is presented in detail by Gkartzonikas and Gkritza [52]. These factors are incorporated into the design of the questionnaire.

The questionnaire was divided into seven sections. The first two sections of the questionnaire focussed on the technological 
savviness and environmental consciousness of the individual. The third, fourth and fifth sections of the questionnaire captured information related to attitudes, subjective norms and perceived behavioural control, respectively. In the third section, respondents are presented with statements related to the potential benefits and impacts of AVs to the individual and society. Statements capturing subjective norms and perceived behavioural control are presented in the fourth and fifth sections of the questionnaire. The statements used in the study are presented later in Table IV. Current travel and sociodemographic characteristics are captured in the sixth and seventh sections. Version "Ver_Lk" used the 5-point Likert scale only, whereas version "Ver_OE" used a combination of 5-point Likert scales and open-ended questions in first, second and third sections of the questionnaire. The survey deployed online presented alternative versions of the questionnaire randomly to the respondents.

The survey was disseminated in India between November 2017 and March 2018 using Facebook and WhatsApp, with the help of bloggers. The collected data were checked for inconsistencies and incomplete records were removed. Also, records of individuals not answering the intention to use SAVs were removed. Later, individuals taking more than an hour to complete the survey were excluded- as we suspect such responses to lack coherence. To deal with respondents answering the questionnaire too quickly (a.k.a. speeders), we relied on the method proposed by Qualtrics [54]. Furthermore, the responses were analysed to identify if respondents answered in patterns (straight-line and diagonal responses). Speeders who also answered in straight lines in at least two or more sections were excluded from further analysis.

\section{DATA DESCRIPTION}

565 (Ver_Lk- 316, Ver_OE- 249) respondents started participating in the survey and 435 (Ver_Lk- 239, Ver_OE196) completed the survey. 38 (15.9\%) respondents from Ver_Lk and $33(16.8 \%)$ respondents from Ver_OE answering too quickly or in patterns were removed. The final dataset (after cleaning) comprises a total of 364 complete responses201 for Ver_Lk and 163 for Ver_OE of the questionnaire respectively. On average, respondents answering Ver_Lk of the questionnaire took 11 minutes 43 seconds (standard deviation- 7 minutes 42 seconds) to complete and those answering Ver_OE took 15 minutes 49 seconds (standard deviation- 8 minutes 39 seconds). The socio-demographic characteristics of the individuals are presented in Table I.

It can be observed that the distributions of the variables are almost similar for the two versions of the questionnaire. The reliance on bloggers could have increased the participation in the survey but might have affected the representativeness of the dataset [55]. To enable a fair comparison of the responses between the two versions of the questionnaire, we evaluated if the obtained samples are comparable. The distributions of the socio-demographic variables answering the alternative versions of the questionnaire were analysed using the Mann-Whitney U test [56]. The differences were not statistically significant.
TABLE I

SOCIO-DEMOGRAPHIC CHARACTERISTICS OF THE INDIVIDUAL

\begin{tabular}{|c|c|c|c|}
\hline Variable & Levels & Ver_Lk & Ver_OE \\
\hline \multirow[t]{2}{*}{$\begin{array}{l}\text { Age } \\
\text { (average) }\end{array}$} & & 30.39 & 29.29 \\
\hline & Female & 24.38 & 26.99 \\
\hline \multirow[t]{3}{*}{ Gender (\%) } & Male & 75.12 & 72.39 \\
\hline & Prefer not to answer & 0.5 & 0.61 \\
\hline & Student & 21.89 & 27.61 \\
\hline \multirow{10}{*}{$\begin{array}{l}\text { Occupation } \\
(\%)\end{array}$} & Postgraduate student & 12.44 & 9.20 \\
\hline & Faculty & 9.95 & 7.98 \\
\hline & Manager & 9.45 & 11.04 \\
\hline & Professional & 35.32 & 35.58 \\
\hline & $\begin{array}{l}\text { Technician and Associate } \\
\text { Professional }\end{array}$ & 3.98 & 1.23 \\
\hline & Others & 2.99 & 4.91 \\
\hline & Unemployed & 1.00 & 1.23 \\
\hline & Prefer not to answer & 2.99 & 1.23 \\
\hline & $0-9,999$ & 12.94 & 15.95 \\
\hline & $10,000-24,999$ & 4.98 & 8.59 \\
\hline \multirow{5}{*}{$\begin{array}{l}\text { Monthly } \\
\text { Household } \\
\text { income in } \\
\text { INR (\%) }\end{array}$} & $25,000-49,999$ & 10.95 & 11.04 \\
\hline & $50,000-74,999$ & 26.87 & 16.56 \\
\hline & $75,000-89,999$ & 12.44 & 18.40 \\
\hline & More than 90,000 & 7.96 & 2.45 \\
\hline & Prefer not to answer & 23.88 & 26.99 \\
\hline
\end{tabular}

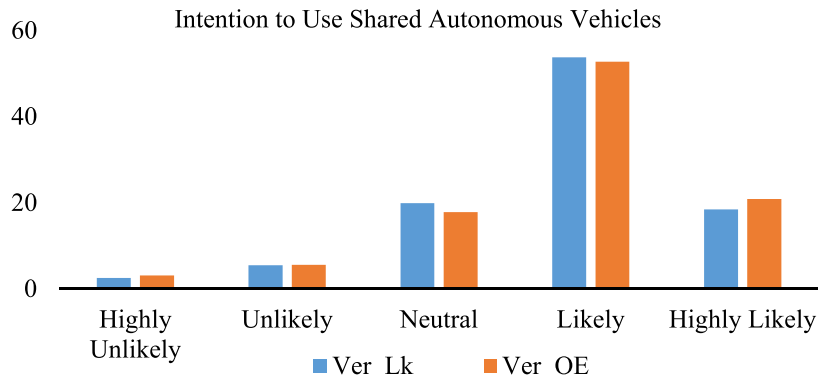

Fig. 1. Frequency Distribution of Intention to Use SAVs.

Referring to Fig 1, a significant percentage of the respondents $(\sim 72 \%)$ for both versions are in favour of using SAVs. Even though our study focussed on SAVs, it is encouraging to observe that it resonate with the findings of Schoettle and Sivak [57], in which respondents from India and China are more positive about using $\mathrm{AVs}$ in general. It is also worth noting that a similar observation regarding the use of pooled $\mathrm{AV}$ s was also made by Stoiber et al. [58]. Respondents answering the attitudinal questions in Ver_OE of the questionnaire were more in favour of using SAVs, however, the increase was only marginal and not statistically significant. We see a small decline in the number of respondents in the "Neutral" category- individuals are slightly more decisive.

When analysing the response to questions measuring the attitudes, the majority of the respondents did not choose the extreme values ("Extremely Unlikely/Strongly Disagree" and "Extremely Likely/Strongly Agree"). Furthermore, the ratings were skewed to the agree/likely side of the Likert scale. Respondents answering Ver_OE were on average more positive (an average change in percentages of $4.8 \%$ ) in their perceptions towards AVs for nearly $2 / 3^{\text {rd }}(14)$ of the questions. 
TABLE II

AVERAGE Number OF WORDS PER RESPONSE

\begin{tabular}{lrrr}
\hline \hline Open-ended Questions & Original & Cleaned \\
\hline $\begin{array}{l}\text { For my travel needs, I use my smartphone for } \\
\text { (OE1) }\end{array}$ & 7.99 & 5.34 \\
$\begin{array}{l}\text { I think transport is a major cause of the } \\
\text { environmental problem, because (OE2) }\end{array}$ & 9.26 & 6.12 \\
$\begin{array}{l}\text { The society will benefit from the use of } \\
\text { Autonomous Vehicles, as it will (OE3) }\end{array}$ & 9.18 & 6.24 \\
$\begin{array}{l}\text { Autonomous Vehicles are likely to impact } \\
\text { society negatively, as (OE4) }\end{array}$ & 11.07 & 6.85 \\
\hline \hline
\end{tabular}

These differences were, however, not statistically significant. Open-ended questions demand the respondent's additional time to think about the answers and to articulate the response. This could potentially influence the thought process of the individual and the responses to the Likert scale questions placed after the open-ended questions.

When asked about the potential impacts of AVs to society, respondents are positive about the societal impacts of AVs. The most appreciated benefit of AVs is the capability of making travel easier for people with driving restrictions. Nearly $70 \%$ of the respondents believe that $\mathrm{AVs}$ will make travel more environmentally friendly and reduce transport induced pollution. Almost an equal proportion of respondents have the notion that AVs will reduce congestion and accidents. When asked about the negative effects, particularly on the employment sector, about $60 \%$ agreed that $\mathrm{AVs}$ could cause unemployment of existing drivers. More than half of the respondents approved that it might create new jobs for skilled workers.

Four open-ended questions were used. Responses were cleaned by removing all punctuations and "stopwords"- some of the most frequently used words that do not convey any specific meaning in this context. Additionally, each of the words was reduced to their root form using "Stemming". The words so obtained are used for analysis. The average number of words used by each respondent in the original response and the cleaned data for each of the open-ended questions is presented in Table II.

We explored the distribution of these cleaned words. Hereafter, we will be referring to the words after stemming and spellings might be different. For the first OE1, "book" (12.10\%), "map" (7.66\%), "ticket" (6.95\%), "googl" (3.95\%) and "find" (3.71\%) were the five most frequently used words. To answer OE2, "pollut" (10.93\%), "emiss" (4.45\%), "vehicle" (3.64\%), "air" (2.53\%) and "fuel" (2.13\%) were used. When asked about the benefits of AVs to the society, respondents used "reduc" (9.76\%), "accid" (4.73\%), "pollut" $(3.12 \%)$, "drive" (2.52\%) and "less" (2.41\%). "Job" (3.74\%), "driver" (2.71\%), "vehicl" (2.43\%), "may" (2.25\%) and "loss" $(2.15 \%)$ were used when asked about the negative impacts of AVs to the society.

\section{Methodology}

The questions about attitudes, subjective norms and perceived behavioural that used Likert scales, were reduced to a smaller number of factors using principal components factor analysis with Varimax rotation [59].

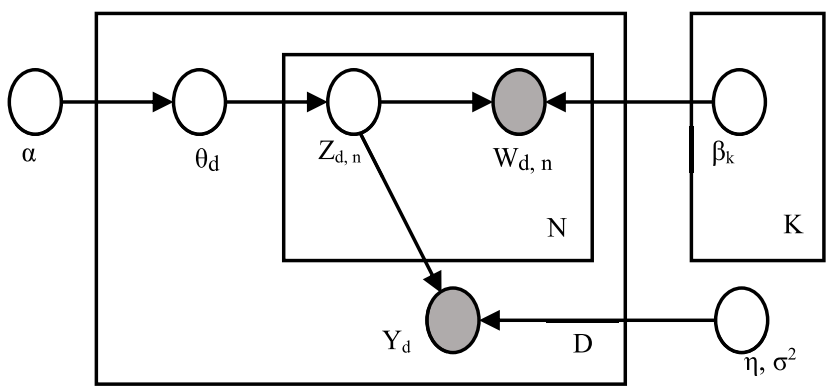

Fig. 2. Probabilistic Graphical Model for sLDA.

To extract information from the four open-ended questions in Ver_OE, LDA and sLDA were used. Before explaining sLDA, we explain LDA- a popular method in Topic Modelling that aims to identify latent constructs in text data. Having such latent variables, we transform each of the open-ended response into numerical values to be used for prediction. LDA is similar to a multinomial principal component analysis (PCA) as LDA converts a text document (represented by word frequencies) into a linear combination of topics (represented by word frequencies). The linear combination of topics is conceptually comparable to the eigenvectors in PCA. In LDA, the given set of documents are represented in the Bag of Words (BoW) format, which is a vector of word frequencies. Using BoW and $\mathrm{K}$ topics, LDA extracts a set of $\mathrm{K}$ topics that minimise the reconstruction error of the original documents. Each of the extracted topics will also be a BoW. When each of the future documents is projected on the topic space, they are re-represented as a combination of $\mathrm{K}$ topics. In addition to the number of topics, LDA requires two additional parameters, $\alpha$ and $\eta$, that determine the sparsity of document-topic and response variable distribution priors respectively [60]. In sLDA, the documents and the responses are modelled jointly to obtain the latent topics that best predict the response variable [61]. In other words, it is a supervised method, where the resulting topics are the ones that maximize the accuracy of a certain model (in our case, predict SAVs acceptance).

The Probabilistic Graphical Model for sLDA is presented in Fig 2. Referring to the figure, the dataset comprises of " $D$ " documents comprising of " $\mathrm{N}$ " words each $\mathrm{W}_{\mathrm{d}, \mathrm{n}}(\mathrm{n}=1 \ldots \mathrm{N}$ and $\mathrm{d}=1 \ldots \mathrm{D})$. Every word is assigned to a topic, among $\mathrm{K}$ available topics. Each topic $\mathrm{k}(\mathrm{k}=1 \ldots \mathrm{K})$ consists of a vector $\beta_{\mathrm{k}}$, that contains the words and associated frequencies in this topic.

The result is that for a given corpus of documents and a response variable, a set of topics that span across every document can be obtained. These set of topics act as their "common building block". Furthermore, for every document, a set of "K" numbers indicating "how much" each of these documents belongs to the building blocks can be obtained. We use them for the estimation of the models. The topics are assessed for their meaningfulness along with the inter-topic distance between the topics. An investigation into the overlap will provide insights on whether the topics are distinct.

The dependent variable of interest in the dataset captured the intention to use SAVs using a 5-point Likert scale ranging from highly unlikely to highly likely. Considering the ordinal 
nature of this variable, ordered Probit model was used in the estimation. For more details about the underlying principle and the estimation techniques of ordered Probit models, readers may refer to the work of [62].

\section{RESUlts AND Discussion}

In the first sub-section, we present the results of the topic models. Later, a discussion on some of the key inferences drawn from the comparison between open-ended and corresponding Likert scale questions is presented. The final two sections discuss the results of the factor analysis and the estimated model for the "intention to use SAVs".

\section{A. Results From the Topic Models}

The responses from the open-ended part were extracted using LDA and sLDA. We do not see an improvement with the use of sLDA over LDA, which could be because of the significant overlap between the topics extracted from LDA and SLDA for our dataset. In the discussions presented below, we will be using the prefix "To_L" for topics extracted using LDA and "To_S" for topics extracted using sLDA. For example, the first topic extracted for OE1 will be labelled To_L11 and To_S11 for LDA and sLDA respectively. The top 5 words of each topic for the open-ended questions are presented in Table III.

Using the responses to OE1 from users, we extracted three different topics (uses of smartphones for travel-related needs). The first was related to the finding places of interest and navigation to the identified place (To_L11/To_S11). Travel planning and finding the status (location and traffic updates) of transport modes was another use of a smartphone (To_L12/To_S12). The third use (To_L13/To_S13) was related to finding hotels and making reservations, flight tickets and taxi services.

The different perspectives of individuals related to the environmental impact of transportation can broadly be classified into three. To_L21/To_S21 was related to pollution (air and noise) and the contribution of transportation induced pollution to global warming. This was driven primarily by the increasing reliance on personal vehicles, due to the lack of public transportation. To_L22/To_S22 also discussed the role of air and noise pollution but emphasised on the wastage of natural resources. To_L23/To_S23 was related to increasing air pollution and dependence on fossil fuels.

The potential benefits of $\mathrm{AVs}$ to society can be categorised into four. Respondents considered AVs futuristic and discussed savings on travel time and resources (To_L31/To_S31). Individuals opined that the use of AVs will probably improve public transport and eliminate the stress of driving (To_L32/To_S32). AVs may reduce accidents due to human errors while minimising pollution (To_L33/To_S33). Increased road efficiency, safety and reduction in fuel usage was the fourth benefit (To_L34/To_S34).

There are three major concerns about the use of AVs, shared by the respondents. Individuals believe that AVs may increase accidents as it is prone to system errors and software hacking (To_L41/To_S41). Individuals share concerns over the loss
TABLE III

TOP 5 WORdS FOR EACH TOPIC FOR OPEN-ENDED QUESTIONS

\begin{tabular}{|c|c|c|c|c|c|}
\hline \multicolumn{6}{|c|}{ OE1- For my travel needs, I use my smartphone for } \\
\hline To_L11 & map & googl & find & rout & locat \\
\hline To_S11 & map & googl & find & place & restaur \\
\hline To_L12 & travel & train & check & time & statu \\
\hline To_S12 & travel & locat & rout & train & check \\
\hline To_L13 & book & ticket & map & hotel & navig \\
\hline To_S13 & book & ticket & navig & map & hotel \\
\hline \multicolumn{6}{|c|}{$\begin{array}{l}\text { OE2- I think, transport is a major cause of environmental problem } \\
\text { because }\end{array}$} \\
\hline To_L21 & emiss & gase & carbon & vehicl & road \\
\hline To_S21 & emiss & gase & carbon & vehicl & road \\
\hline To_L22 & pollut & air & sound & traffic & nois \\
\hline To_S22 & pollut & air & traffic & nois & sound \\
\hline To_L23 & vehicl & fuel & transport & exhaust & public \\
\hline To_S23 & vehicl & fuel & transport & public & increas \\
\hline \multicolumn{6}{|c|}{$\begin{array}{l}\text { OE3- The society will benefit from the use of Autonomous Vehicles, as } \\
\text { it will }\end{array}$} \\
\hline To_L31 & time & save & traffic & product & resourc \\
\hline To_S31 & time & traffic & save & product & safe \\
\hline To_L32 & drive & transport & travel & help & peopl \\
\hline To_S32 & drive & transport & travel & help & peopl \\
\hline To_L33 & reduc & accid & pollut & less & human \\
\hline To_S33 & reduc & accid & pollut & less & human \\
\hline To_L34 & effici & road & increas & driver & safeti \\
\hline To_S34 & effici & road & increas & driver & safeti \\
\hline \multicolumn{6}{|c|}{ OE4- Autonomous Vehicles are likely to impact society negatively, as } \\
\hline To_L41 & vehicl & may & accid & lead & hack \\
\hline To_S41 & vehicl & may & accid & lead & increas \\
\hline To_L42 & job & driver & loss & peopl & drive \\
\hline To_S42 & job & driver & loss & peopl & drive \\
\hline To_L43 & human & car & control & traffic & reduc \\
\hline To_S43 & car & control & system & technolog & human \\
\hline \multicolumn{6}{|c|}{ Words in both LDA and sLDA for the same topic in the same order } \\
\hline \multicolumn{6}{|c|}{ Words in both LDA and sLDA for the same topic in a different order } \\
\hline
\end{tabular}

of employment, particularly of drivers (To_L42/To_S42). The third topic (To_L43/To_S43) discussed mostly the technological needs for such a control system and its associated safety.

To analyse if the extracted topics are distinct, we computed the inter-topic distance. The results were presented visually using pyLDAvis [63]. There is no overlap between the extracted topics, which has the positive side-effect of reducing multicollinearity.

\section{B. Comparison of Likert Scale and Open-Ended Questions}

We analysed if we could find a correspondence between the open- and closed-ended responses. Open-ended questions can be considered appropriate for measuring attitudes if the topics extracted from open-ended questions are related to the statements presented in Likert scale questions.

To begin with, we tested the internal reliability of the Likert scale responses using Cronbach's Alpha values. The estimated values for "Ver_Lk" and "Ver_OE" of the questionnaire were 0.831 and 0.830 respectively- indicating the questionnaire to be reliable. To test the validity of the questionnaire, we compared the average scores for the Likert scale responses among two groups (does not follow news about AVs v/s follow news about $\mathrm{AVs}$ ). Respondents following news about AVs 
seem to have answered responded correctly to the statements. The differences between the two groups were statistically significant (t-stats) for both versions ("Ver_Lk"- 14.65 and "Ver_OE"-9.49) of the questionnaire indicating the validity of the questionnaire.

In three out of the four open-ended questions used in this research, we found similarities between the extracted topics and the statements used for the Likert scales. For the questions related to transportation induced environmental problems, the topics extracted from open-ended questions did not identify the need for huge infrastructure but identified other aspects used in Likert scale questions. Infrastructure improvements may be considered a necessity for mobility which could probably be the reason for people to not have identified it as an environmental issue. However, open-ended responses also discussed the link between transportation and global warming. For the question related to the potential benefits of AVs, the responses mostly covered aspects related to increased traffic efficiency, fuel efficiency, savings in travel times, reduced pollution and accidents. The respondents did not discuss the potential of AVs to reduce demand for parking spaces or address gender equity issues related to mobility. Respondents answering the open-ended question related to the potential impacts of $\mathrm{AVs}$ to society did cover some of the actual concerns related to its implementation such as loss of employment opportunities, the potential for system failures and hacking and the need a costly and sophisticated control system.

The open-ended question on the use of smartphones for travel needs "OE1", is an illustration of the need for a careful design of open-ended questions. The closed-ended question focussed on the frequency of use of smartphones for various travel needs, however, our open-ended question was targeted at identifying the uses. There is no correspondence and hence cannot be used for the estimation of the models. However, we would like to emphasize, that we could extract meaningful topics from the responses to this question.

\section{Results of Factor Analysis}

Factor analysis was performed on the attitudinal questions presented on a 5-point Likert scale. For consistency, the same number of factors are estimated for both datasets. The results are presented below in Table IV. Kaiser-Meyer-Olkin (KMO) statistics for the factors are found reasonable. These factors are used in the estimation of the model for predicting the intention to use SAVs.

For the question related to the potential benefits of AVs to society, two factors "Positive benefits of AVs on society 1" and "Positive benefits of AVs on society 2" were extracted. "Positive benefits of AVs on society 1 " encompasses the benefits in terms of making travel more environmentally friendly, less polluting and safe- by reducing accidents. "Positive benefits of AVs on society 2" represents benefits such as reducing gender equity issues in travel and making travel easier for people who cannot otherwise drive. Reduction in congestion and accidents are other benefits accounted for, by both factors. The influence of AVs on employment is captured by "AVs impact on employment".
TABLE IV

RESUlTS OF FACTOR ANALYSis

\begin{tabular}{|c|c|c|}
\hline Factors & Ver_Lk & Ver_OE \\
\hline \multicolumn{3}{|l|}{ Positive Benefits of AVs on Society 1} \\
\hline KMO & 0.793 & \\
\hline \multicolumn{3}{|l|}{ Autonomous Vehicles will impact society by } \\
\hline Making travel more environmentally friendly & 0.856 & \\
\hline Reducing traffic congestion in cities & 0.609 & \\
\hline Reducing transportation induced pollution & 0.868 & \\
\hline Making travel safer by reducing accidents & 0.527 & \\
\hline Reducing the need for parking spaces & 0.566 & \\
\hline \multicolumn{3}{|l|}{ Positive Benefits of AVs on Society 2} \\
\hline KMO & 0.793 & \\
\hline \multicolumn{3}{|l|}{ Autonomous Vehicles will impact society by } \\
\hline Reducing traffic congestion in cities & 0.485 & \\
\hline Making travel safer by reducing accidents & 0.588 & \\
\hline $\begin{array}{l}\text { Making travel easier to people who cannot } \\
\text { otherwise drive }\end{array}$ & 0.769 & \\
\hline Reducing gender equity issues in travel & 0.729 & \\
\hline \multicolumn{3}{|l|}{ AVs Impact on employment } \\
\hline KMO & 0.500 & \\
\hline \multicolumn{3}{|l|}{ Autonomous Vehicles will impact society by } \\
\hline Causing unemployment of existing drivers & 0.732 & \\
\hline Creating new jobs for skilled workers & -0.732 & \\
\hline \multicolumn{3}{|l|}{ Positive attitudes of individuals on AVs- PAT } \\
\hline KMO & 0.727 & 0.717 \\
\hline I think it will be cool to use AVs & 0.753 & 0.799 \\
\hline I can involve in other activities during travel & 0.811 & 0.787 \\
\hline I will be relieved from the stress of driving & 0.820 & 0.779 \\
\hline I can eliminate the parking-related issues & 0.722 & 0.661 \\
\hline \multicolumn{3}{|l|}{ Subjective Norms- $S N$} \\
\hline KMO & 0.727 & 0.717 \\
\hline \multicolumn{3}{|l|}{ I think my friends and family } \\
\hline Will use AVs & 0.672 & 0.735 \\
\hline Believe, AVs will reduce congestion & 0.695 & 0.795 \\
\hline Believe, AVs will reduce pollution & 0.681 & 0.791 \\
\hline $\begin{array}{l}\text { Believe, AVs will make travel safer, by } \\
\text { reducing accidents }\end{array}$ & 0.801 & 0.740 \\
\hline Will be positive about me using AVs & 0.803 & 0.846 \\
\hline \multicolumn{3}{|l|}{ Perceived behavioural control variables 1- $P B 1$} \\
\hline KMO & 0.686 & 0.653 \\
\hline $\begin{array}{l}\text { I am confident the system will be protected } \\
\text { against hacking and failures }\end{array}$ & 0.776 & 0.737 \\
\hline $\begin{array}{l}\text { I am confident that the interaction with other } \\
\text { vehicles will be safe }\end{array}$ & 0.802 & 0.818 \\
\hline I believe this will make my travel more efficient & 0.799 & 0.711 \\
\hline $\begin{array}{l}\text { I believe AVs will make travel more } \\
\text { environmentally friendly }\end{array}$ & 0.706 & 0.704 \\
\hline \multicolumn{3}{|l|}{ Perceived behavioural control variables $2-P B 2$} \\
\hline KMO & 0.686 & 0.653 \\
\hline $\begin{array}{l}\text { I am worried about the liabilities after an } \\
\text { accident }\end{array}$ & 0.684 & 0.466 \\
\hline $\begin{array}{l}\text { I have concerns regarding payment for the } \\
\text { service }\end{array}$ & 0.790 & 0.858 \\
\hline I think AVs will not be affordable to me & 0.706 & 0.598 \\
\hline
\end{tabular}

The factor "positive attitude of the individual on AVs" includes the notion of using AV as being "cool". In addition to this, the benefits from elimination of parking-related issues, stress from driving and the ability to perform other activities 
during travel are also captured by this factor. The perception that friends and family will use AVs, will be positive about the individual using $\mathrm{AV}$, them believing that $\mathrm{AVs}$ will reduce congestion, pollution and accidents are captured by the factor "Subjective norms". The confidence that the system will be conducive for use is captured by "Perceived behavioural control variables 1", whereas the concerns that may remain unaddressed is represented by "Perceived behavioural control variables 2". "Perceived behavioural control variables 1" includes the belief that the system will be protected against failures and hacking and that the interaction with other vehicles will be safe. It also covers the confidence that use of AVs will ensure that the travel is more environmentally friendly and efficient. The concerns about the payment system, liabilities in the event of an accident and affordability are captured by "Perceived behavioural control variables 2".

\section{Model Estimation and Discussion of Results}

For both versions of the questionnaire, we estimate a model " $\mathrm{M}_{\mathrm{I}}$ " using variables related to the Theory of Planned Behaviour only. Later, for each version of the questionnaire, we included variables related to the environmental effects of transportation. For Ver_Lk, we introduce the variable "Role_Pol" with the corresponding model being named " $\mathrm{M}_{\mathrm{F}}$ ". For Ver_OE, we estimated two models by including the topics related to the environmental effects of transportation induced pollution- "M $\mathrm{LDA}_{\text {L }}$ " (using LDA) and "M sLDA). Notice that we only have one topic variable, as only this variable was statistically significant. This is discussed in detail in the subsequent paragraph. The relative performance of each of these models is compared. The models were estimated using a training set (90\%) and test set (10\%). Table $\mathrm{V}$ presents the estimation results for the training set for the intention to use SAVs. The threshold parameters for the ordered Probit model along with initial log-likelihood $\left(\mathrm{LL}_{\mathrm{I}}\right)$, final log-likelihood $\left(\mathrm{LL}_{\mathrm{F}}\right)$ and McFadden pseudo-Rsquared value $\left(\rho^{2}\right)$ are also presented. $\mathrm{M}_{\mathrm{I}}$ had a $\rho^{2}$ value of 0.16 , and there was no improvement with the addition of the environmental pollution-related variable $\left(\mathrm{M}_{\mathrm{F}}\right)$ for Ver_Lk. The performance of the model was superior for Ver_OE of the questionnaire. $\mathrm{M}_{\mathrm{I}}$ for Ver_OE had a $\rho^{2}$ value of 0.227 , which improved to 0.242 and 0.245 for $M_{\text {LDA }}$ and MSLDA respectively. A similar improvement can be observed for other goodness-of-fit measures also. Questions related to the pollution asked in Ver_Lk of the questionnaire did not improve the performance of the model. This could be because of the very small variability in the response to the Likert scale question. However, in Ver_OE, there was an improvement with the addition of the topic variable related to pollution. This could be because this variable (To_L23/To_S23) extracted more relevant information compared to the Likert scale question on pollution. It also captured the underlying factor- increase in vehicles, lack of public transport.

For both versions of the questionnaire, positive attitudes of the individual on $\mathrm{AVs}$ is associated with an increase in the intention to use SAVs. The coefficients are, however, statistically significant only for Ver_OE of the questionnaire.
TABLE V

Estimation Results of the MOdEl FOR "INTENTION to USE SAVs"

\begin{tabular}{|c|c|c|c|c|c|}
\hline \multirow{2}{*}{ Variable } & \multicolumn{2}{|c|}{ Ver_Lk } & \multicolumn{3}{|c|}{ Ver_OE } \\
\hline & $\mathrm{M}_{\mathrm{I}}$ & $\mathrm{M}_{\mathrm{F}}$ & $\mathrm{M}_{\mathrm{I}}$ & $\mathrm{M}_{\mathrm{LDA}}$ & $\mathrm{M}_{\mathrm{SLDA}}$ \\
\hline Constant & $\begin{array}{r}2.568 \\
* * *\end{array}$ & $\begin{array}{r}2.615 \\
* * *\end{array}$ & $\begin{array}{r}2.683 \\
* * *\end{array}$ & 2.612 & 2.608 \\
\hline & $* * *$ & $* * *$ & $\begin{array}{r}* * * \\
0446\end{array}$ & $\begin{array}{r}* * * \\
0472\end{array}$ & $\begin{array}{r}* * * \\
0477\end{array}$ \\
\hline PAT & 0.167 & 0.170 & $\begin{array}{r}0.446 \\
* * *\end{array}$ & $\begin{array}{r}0.4 / 2 \\
* * *\end{array}$ & $* * *$ \\
\hline $\mathrm{SN}$ & $\begin{array}{r}0.369 \\
* * *\end{array}$ & $\begin{array}{r}0.374 \\
* * *\end{array}$ & $\begin{array}{r}0.273 \\
* * *\end{array}$ & 0.217 & 0.209 \\
\hline PB1 & $\begin{array}{r}0.388 \\
* * *\end{array}$ & $\begin{array}{r}0.388 \\
* * *\end{array}$ & $\begin{array}{r}0.381 \\
* * *\end{array}$ & $\begin{array}{r}0.432 \\
* * *\end{array}$ & $\begin{array}{r}0.440 \\
* * *\end{array}$ \\
\hline PB2 & 0.087 & 0.087 & $\begin{array}{r}-0.182 \\
*\end{array}$ & $\begin{array}{r}-0.212 \\
* *\end{array}$ & $\begin{array}{r}-0.217 \\
* *\end{array}$ \\
\hline Role_Poll & & -0.065 & & & \\
\hline To_L-23/ & & & & 1.799 & 1.979 \\
\hline To_S23 & & & & $* *$ & $* * *$ \\
\hline \multicolumn{6}{|c|}{ Threshold parameters for the index } \\
\hline $\mathrm{Mu}(01)$ & $\begin{array}{r}0.873 \\
* * *\end{array}$ & $\begin{array}{r}0.872 \\
* * *\end{array}$ & $\begin{array}{r}0.833 \\
* * *\end{array}$ & $\begin{array}{r}0.865 \\
* * *\end{array}$ & $\begin{array}{r}0.872 \\
* * *\end{array}$ \\
\hline $\mathrm{Mu}(02)$ & $\begin{array}{r}1.906 \\
* * *\end{array}$ & $\begin{array}{r}1.903 \\
* * *\end{array}$ & $\begin{array}{r}1.839 \\
* * *\end{array}$ & $\begin{array}{r}1.900 \\
* * *\end{array}$ & $\begin{array}{r}1.915 \\
* * *\end{array}$ \\
\hline $\mathrm{Mu}(03)$ & $\begin{array}{r}3.771 \\
* * *\end{array}$ & $\begin{array}{r}3.769 \\
* * *\end{array}$ & $\begin{array}{r}3.773 \\
* * *\end{array}$ & $\begin{array}{r}3.872 \\
* * *\end{array}$ & $\begin{array}{r}3.896 \\
* * *\end{array}$ \\
\hline \multicolumn{6}{|c|}{ Goodness-of-fit measures } \\
\hline Sample size & & & & 145 & \\
\hline $\mathrm{LL}_{\mathrm{I}}$ & -22 & & & -181.119 & \\
\hline $\mathrm{LL}_{\mathrm{F}}$ & 187.196 & $187.143^{-}$ & 140063 & 137331 & 136823 \\
\hline$\rho^{2}$ & $\begin{array}{r}187.190 \\
0.160\end{array}$ & $\begin{array}{r}18.143 \\
0.161\end{array}$ & $\begin{array}{r}140.003 \\
0.227\end{array}$ & $\begin{array}{r}13.331 \\
0.242\end{array}$ & $\begin{array}{r}130.823 \\
0.245\end{array}$ \\
\hline Adj. $\rho^{2}$ & 0.125 & 0.120 & 0.183 & 0.192 & 0.195 \\
\hline Count $\mathrm{R}^{2}$ & 0.552 & 0.552 & 0.579 & 0.600 & 0.607 \\
\hline Adj. Count $\mathrm{R}^{2}$ & 0.172 & 0.172 & 0.218 & 0.247 & 0.250 \\
\hline
\end{tabular}

It can also be observed that a positive perception among friends and family and their supportive nature also contributes positively to the intention to use SAVs. The coefficient for subjective norms loses its statistical significance for $M_{L D A}$ and $\mathrm{M}_{\mathrm{SLDA}}$ in the $90 \%$ training set. However, the variable is statistically significant for the full dataset (100\% observations) and hence, we suspect this likely loss of statistical significance in the training set (for $\mathrm{M}_{\mathrm{LDA}}$ and $\mathrm{M}_{\mathrm{SLDA}}$ ) to be due to the low sample size (145 observations). The factor related to the confidence in the system has a positive and statistically significant coefficient for both versions of the questionnaire. This emphasises the need to improve the confidence that the system is protected against hacking and failures and that the interaction with other vehicles is safe. The factor capturing the concerns associated with the use of $\mathrm{AVs}$ such as affordability, liabilities in the event of an accident and payment for the service influences negatively the intention to use SAVs in Ver_OE. The factor has, however, a positive and statistically insignificant coefficient for Ver_Lk of the questionnaire. When comparing the coefficients, it can be observed that the factor associated with the positive benefits of $\mathrm{AVs}$ and the concerns with AVs is not statistically significant for Ver_Lk, but it is significant for Ver_OE. Between the two versions, the only difference is the introduction of open-ended questions related to the potential benefits and issues with the use of AVs. Answering these questions would have demanded additional thinking from the respondents. This could explain the difference in the coefficients. Moreover, this might have eliminated the careless responding to Likert scale questions. 
TABLE VI

COMPARISON OF THE GOODNESS-OF-FIT MEASURES FOR THE Training SET and Test SET

\begin{tabular}{lrrrrr}
\hline \hline & \multicolumn{1}{c}{ Ver_Lk } & Ver_OE \\
\hline & $\mathrm{M}_{\mathrm{I}}$ & \multicolumn{1}{c}{$\mathrm{M}_{\mathrm{F}}$} & $\mathrm{M}_{\mathrm{I}}$ & $\mathrm{M}_{\text {LDA }}$ & $\mathrm{M}_{\text {sLDA }}$ \\
\hline Ln (0) & \multicolumn{6}{c}{$90 \%$ Training Set } \\
& -222.955 & & -181.119 \\
Ln (Final) & - & - & - & - & - \\
& 187.196 & 187.143 & 140.063 & 1 & 136.823 \\
Rho-sq & 0.160 & 0.161 & 0.227 & 0.242 & 0.245 \\
K & 8 & 9 & 8 & 9 & 9 \\
Adj Rho-sq & 0.125 & 0.120 & 0.183 & 0.192 & 0.195 \\
Count R Sq & 0.552 & 0.552 & 0.579 & 0.600 & 0.607 \\
Adj Count R Sq & 0.172 & 0.172 & 0.218 & 0.247 & 0.250 \\
F1 Score & 0.389 & 0.389 & 0.539 & 0.497 & 0.534 \\
\hline \multicolumn{7}{c}{$10 \%$ Test Set } & & \\
\hline Ln (0) & \multicolumn{7}{c}{-28.970} & & & -28.97 \\
Ln (Final) & -21.001 & -20.883 & -19.151 & -19.245 & -19.271 \\
Rho-sq & 0.275 & 0.279 & 0.339 & 0.336 & 0.335 \\
K & 8 & 9 & 8 & 9 & 9 \\
Adj Rho-sq & -0.001 & -0.032 & 0.063 & 0.025 & 0.024 \\
Count R Sq & 0.500 & 0.500 & 0.786 & 0.786 & 0.786 \\
Adj Count R Sq & 0.100 & 0.100 & 0.250 & 0.250 & 0.250 \\
F1 Score & 0.244 & 0.244 & 0.369 & 0.273 & 0.369 \\
\hline \hline
\end{tabular}

As reported earlier, we see an improvement in the perceptions towards AVs and its use among respondents answering Ver_OE of the questionnaire. This could be because answering the open-ended questions could have made them provide answers based on more deliberative reasoning. Respondents who believe that transportation is a major source of environmental pollution are more likely to use SAVs, probably because of the notion that shared systems are more sustainable. The effect is however not observed for Ver_Lk of the questionnaire, in which a Likert scale question was used. We also tested the effect of the benefits of AVs to the society (using a factor for Ver_Lk and topics for Ver_OE) on the intention to use SAVs. The variables were not statistically significant, probably because respondents are more focussed on the potential benefits to the individual and not to the society.

To test the predictive capability of the estimated models, we applied the models to predict the intention to use SAVs using a test set with $10 \%$ randomly selected observations. The performance of the goodness-of-fit measures for both the training set and the test set is tabulated in Table VI. It can be observed that the performance of the models is better for Ver_OE in comparison to Ver_Lk. A similar trend can be observed for the test set also. When computing the adjusted $\rho^{2}$, negative values were obtained for the test set for Ver_Lk. This is because, while accounting for the number of estimated parameters, the final log-likelihood was less than the initial log-likelihood. To account for precision and recall, we computed the $F_{1}$ scores. These scores are also superior for Ver_OE of the questionnaire for both, the training set and test set. The use of supervised approach (sLDA) did not improve the performance of the model compared to the unsupervised approach (LDA).

\section{CONCLUSION}

Open-ended questions were used to measure the attitudes influencing the intention to use SAVs. The alternative versions of the questionnaire were distributed randomly to the respondents. There were no statistically significant differences in the distributions of socio-demographic and travel characteristics of the respondents answering the alternative versions of the questionnaire.

The ratings were higher for $2 / 3^{\text {rd }}$ of the questions among respondents answering Ver_OE of the questionnaire. This could imply a change in the thought process and could also be the possible reason for the slightly higher decisiveness in the intention to use SAVs among respondents answering Ver_OE of the questionnaire. It must, however, be emphasised that these differences were not statistically significant. So, this should be explored further using data from other countries and larger datasets.

To extract information from the open-ended responses, LDA and SLDA were used. The inter-topic distance between the extracted topics indicated that the extracted topics were distinct. For most of the open-ended questions, we could find a correspondence to a certain extent with the Likert scale questions. The inclusion of open-ended response related to the role of transport-induced pollution had a positive influence on the intention to use SAVs. This also had a corresponding influence on the goodness-of-fit of the estimated models. The attitudinal variables in Ver_Lk corresponding to this open-ended question did not turn out to be statistically significant. The models estimated using Ver_OE of the questionnaire outperformed the models estimated using Ver_Lk of the questionnaire for both, the training set and the test set. We could not see an improvement in the performance of the model with the use of sLDA over LDA. These results and the potential to alter the reasoning process emphasize the potential for use of open-ended responses to measure attitudes and topic models for extracting open-ended responses. To overcome the burden on respondents in writing responses to open-ended questions, they can be encouraged to speak. Combining these two will reduce the time required to collect and analyse open-ended responses significantly. This will open up new avenues for policymakers and analysts for measuring attitudes in travel behaviour research.

The positive attitude of an individual towards the use of AVs and subjective norms influence positively the intention to use SAVs for Ver_OE of the questionnaire. The coefficient was statistically significant for the full dataset; however, the coefficient lost its statistical significance for the training set comprising $90 \%$ responses. This we believe, could be related to the low sample size. Perceived behavioural control variable related to having a conducive environment positively influenced the intention to use SAVs, whereas perceived behavioural control variable related to concerns negatively influenced the intention to use SAVs. This effect is observed only for Ver_OE of the questionnaire. The results indicate the ability of TPB to measure the intention to use SAVs.

Having demonstrated the potential to use open-ended questions to measure attitudes, it would be advisable to investigate this further using a larger dataset. We believe the use of larger dataset will improve the quality of the extracted topics. Being an online survey, where participation was mostly voluntary, we could not ensure the representativeness of the sample. Our data had a higher proportion of males, who were mostly 
young or middle-aged. Considering this, further analysis using a sample that is representative of the population is imperative. Furthermore, it would be appropriate to use statements in the Likert scale questions that have been tested extensively to compare the performance with open-ended questions. With regards to the use of topic models, a possibility could be to avoid the splitting of noun-noun compounds (public transportation, global warming) in the data.

\section{REFERENCES}

[1] S. Amin, "The psychology of coronavirus fear: Are healthcare professionals suffering from corona-phobia?" Int. J. Healthcare Manage., vol. 13, no. 3, pp. 249-256, Jul. 2020.

[2] L. Drabwell, J. Eng, F. Stevenson, M. King, D. Osborn, and A. Pitman, "Perceptions of the use of alcohol and drugs after sudden bereavement by unnatural causes: Analysis of online qualitative data," Int. J. Environ. Res. Public Health, vol. 17, no. 3, p. 677, Jan. 2020.

[3] J. G. Geer, "Do open-ended questions measure 'Salient' issues?" Public Opinion Quart., vol. 55, no. 3, p. 360, 1991.

[4] J. G. Geer, "What do open-ended questions measure," Public Opinion Quart., vol. 52, no. 3, pp. 365-371, 1988.

[5] L. Buccoliero, E. Bellio, G. Crestini, and A. Arkoudas, "Twitter and politics: Evidence from the US presidential elections 2016," J. Marketing Commun., vol. 26, no. 1, pp. 88-114, Jan. 2020.

[6] K. Schmidt, T. Gummer, and J. Roßmann, "Effects of respondent and survey characteristics on the response quality of an open-ended attitude question in Web surveys," Methods, Data, Anal., vol. 14, no. 1, pp. 3-34, 2020.

[7] S. Kaplan, F. Manca, T. A. S. Nielsen, and C. G. Prato, "Intentions to use bike-sharing for holiday cycling: An application of the theory of planned Behavior," Tourism Manage., vol. 47, pp. 34-46, Apr. 2015.

[8] R. Kelkel, Predicting Consumers' Intention to Purchase Fully Autonomous Driving Systems-Which Factors Drive Acceptance. Lisbon, Portugal: Universidade Católica Portuguesa, 2015.

[9] S. Kaplan, J. de Abreu e Silva, and F. Di Ciommo, "The relationship between young people's transit use and their perceptions of equity concepts in transit service provision," Transp. Policy, vol. 36, pp. 79-87, Nov. 2014.

[10] K. K. Srinivasan and P. Bhargavi, "Longer-term changes in mode choice decisions in chennai: A comparison between cross-sectional and dynamic models," Transportation, vol. 34, no. 3, pp. 355-374, May 2007.

[11] H. Iversen, "Risk-taking attitudes and risky driving behaviour," Transp. Res. F, Traffic Psychol. Behav., vol. 7, no. 3, pp. 135-150, May 2004.

[12] C.-F. Chen, "Personality, safety attitudes and risky driving BehaviorsEvidence from young taiwanese motorcyclists," Accident Anal. Prevention, vol. 41, no. 5, pp. 963-968, Sep. 2009.

[13] J. M. Converse, "Strong arguments and weak evidence: The open/closed questioning controversy of the 1940s," Public Opinion Quart., vol. 48, no. 1B, pp. 267-282, Mar. 1984.

[14] J. A. Krosnick, "Questionnaire design," in The Palgrave Handbook of Survey Research, D. L. Vannette and J. A. Krosnick, Eds. London, U.K.: Palgrave Macmillan, 2018, pp. 439-455.

[15] R. Tourangeau and K. A. Rasinski, "Cognitive processes underlying context effects in attitude measurement.," Psychol. Bull., vol. 103, no. 3, pp. 299-314, 1988.

[16] J. A. Krosnick and L. R. Fabrigar, "Designing rating scales for effective measurement in surveys," in Survey Measurement and Process Quality, L. Lyberg, P. Biemer, M. Collins, E. De Leeuw, C. Dippo, N. Schwarz, and D. Trewin, Eds. New York, NY, USA: Wiley, 1997, pp. 141-164.

[17] A. Bowling, "Handbook of Health research methods," in Handbook of Health Research Methods-Investigation, Measurement and Analysis, A. Bowling and S. Ebrahim, Eds. Omaha, NE, USA: Berkshire, 2005, pp. 394-427.

[18] A. W. Bendig, "The reliability of self-ratings as a function of the amount of verbal anchoring and of the number of categories on the scale.," J. Appl. Psychol., vol. 37, no. 1, pp. 38-41, Feb. 1953.

[19] C. C. Preston and A. M. Colman, "Optimal number of response categories in rating scales: Reliability, validity, discriminating power, and respondent preferences," Acta Psychologica, vol. 104, no. 1, pp. 1-15, Mar. 2000.

[20] M. Borjas, An Evaluation of the Number of Response Options for Scales in Psychology. Houston, TX, USA: Univ. Houston, 2020.
[21] L. J. Simms, K. Zelazny, T. F. Williams, and L. Bernstein, "Does the number of response options matter? Psychometric perspectives using personality questionnaire data," Psychol. Assess., vol. 31, no. 4, pp. 557-566, 2019.

[22] M. Diana, "Measuring the satisfaction of multimodal travelers for local transit services in different urban contexts," Transp. Res. A, Policy Pract., vol. 46, no. 1, pp. 1-11, Jan. 2012.

[23] V. Baburajan, J. De Abreu e Silva, and F. C. Pereira, "Opening up the conversation: Topic modeling for automated text analysis in travel surveys," in Proc. 21 st Int. Conf. Intell. Transp. Syst. (ITSC), Nov. 2018, pp. 3657-3661.

[24] A. A. de Souza, S. P. Sanches, and M. A. G. Ferreira, "Influence of attitudes with respect to cycling on the perception of existing barriers for using this mode of transport for commuting," Procedia Social Behav. Sci., vol. 162, pp. 111-120, Dec. 2014.

[25] R. Garland, "The mid-point on a rating scale: Is it desirable," Mark. Bull., vol. 2, pp. 66-70, May 1991.

[26] M. S. Matell and J. Jacoby, "Is there an optimal number of alternatives for likert-scale items? Effects of testing time and scale properties.", J. Appl. Psychol., vol. 56, no. 6, pp. 506-509, 1972.

[27] T. Wells, J. T. Bailey, and M. W. Link, "Comparison of smartphone and online computer survey administration," Social Sci. Comput. Rev., vol. 32, no. 2, pp. 238-255, Apr. 2014.

[28] B. Weijters, K. Millet, and E. Cabooter, "Extremity in horizontal and vertical likert scale format responses. Some evidence on how visual distance between response categories influences extreme responding," Int. J. Res. Marketing, to be published. [Online]. Available: https://www.sciencedirect.com/science/article/pii/S0167811620300367? casa_token=-pvmxo5GqEUAAAAA:EJNA1CVazOybR6XeEmAqp2Vs K6DYWBh0BeoxzuDbh5p4Y_MpHvvL_Gr7-d1u1H-2iwO5BG4msw

[29] J. A. Krosnick and S. Presser, "Question and questionnaire design," in Handbook of Survey Research, vol. 112, no. 3, 2nd ed. Bingley, U.K.: Emerald Group Publishing Limited, 2010, pp. 263-313.

[30] D. Rugg and H. Cantril, "The wording of questions in public opinion polls," J. Abnorm. Soc. Psychol., vol. 37, no. 4, pp. 469-495, 1942.

[31] P. F. Lazarsfeld, "The controversy over detailed interviews-an offer for negotiation," Public Opinion Quart., vol. 8, no. 1, pp. 38-60, 1944.

[32] J. E. Stanga and J. F. Sheffield, "The myth of zero partisanship: Attitudes toward American political parties, 1964-84," Amer. J. Political Sci., vol. 31, no. 4, pp. 829-855, 1987.

[33] J. D. Smyth, D. A. Dillman, L. M. Christian, and M. McBride, "Openended questions in Web surveys can increasing the size of answer boxes and providing extra verbal instructions improve response quality," Public Opinion Quart., vol. 73, no. 2, pp. 325-337, 2009.

[34] J. L. Holland and L. M. Christian, "The influence of topic interest and interactive probing on responses to open-ended questions in Web surveys," Social Sci. Comput. Rev., vol. 27, no. 2, pp. 196-212, May 2009.

[35] A. Peytchev, "Survey breakoff," Public Opinion Quart., vol. 73, no. 1, pp. 74-97, 2009.

[36] F. C. Pereira, F. Rodrigues, E. Polisciuc, and M. Ben-Akiva, "Why so many people? Explaining nonhabitual transport overcrowding with Internet data," IEEE Trans. Intell. Transp. Syst., vol. 16, no. 3, pp. 1-10, Jan. 2015

[37] I. Markou, F. Rodrigues, and F. C. Pereira, "Is travel demand actually deep? An application in event areas using semantic information," IEEE Trans. Intell. Transp. Syst., vol. 21, no. 2, pp. 641-652, Feb. 2020.

[38] T. Kurashima, T. Iwata, G. Irie, and K. Fujimura, "Travel route recommendation using geotagged photos," Knowl. Inf. Syst., vol. 37, no. 1, pp. 37-60, Oct. 2013

[39] Z. Xu, L. Chen, and G. Chen, "Topic based context-aware travel recommendation method exploiting geotagged photos," Neurocomputing, vol. 155, pp. 99-107, May 2015.

[40] Z. Zhao, H. N. Koutsopoulos, and J. Zhao, "Discovering latent activity patterns from transit smart card data: A spatiotemporal topic model," Transp. Res. C, Emerg. Technol., vol. 116, Jul. 2020, Art. no. 102627.

[41] J. Wang, X. Chen, Z. Chen, and L. Mao, "Cluster algorithm based on LDA model for public transport passengers' trip purpose identification in specific area," in Proc. IEEE Int. Conf. Intell. Transp. Eng. (ICITE), Aug. 2016, pp. 186-192.

[42] S. Hasan and S. V. Ukkusuri, "Urban activity pattern classification using topic models from online Geo-location data," Transp. Res. C, Emerg. Technol., vol. 44, pp. 363-381, Jul. 2014.

[43] M. E. Roberts et al., "Structural topic models for open-ended survey responses," Amer. J. Political Sci., vol. 58, no. 4, pp. 1064-1082, Oct. 2014 
[44] A.-S. Pietsch and S. Lessmann, "Topic modeling for analyzing openended survey responses," J. Bus. Anal., vol. 1, no. 2, pp. 93-116, Jul. 2018.

[45] E. Tvinnereim and K. Fløttum, "Explaining topic prevalence in answers to open-ended survey questions about climate change," Nature Climate Change, vol. 5, no. 8, pp. 744-747, Aug. 2015.

[46] S. Mitsui, T. Kubo, and Y. Shoji, "Understanding residents' perceptions of nature and local economic activities using an open-ended question before protected area designation in Amami Islands, Japan," J. Nature Conservation, vol. 56, Aug. 2020, Art. no. 125857.

[47] I. Ajzen, "The theory of planned behavior," Org. Behav. Hum. Decision Process., vol. 50, no. 2, pp. 179-211, 1991.

[48] P. S. Lavieri, V. M. Garikapati, C. R. Bhat, R. M. Pendyala, S. Astroza, and F. F. Dias, "Modeling individual preferences for ownership and sharing of autonomous vehicle technologies," Transp. Res. Rec., J. Transp. Res. Board, vol. 2665, no. 1, pp. 1-10, Jan. 2017.

[49] P. Bansal, K. M. Kockelman, and A. Singh, "Assessing public opinions of and interest in new vehicle technologies: An Austin perspective," Transp. Res. C, Emerg. Technol., vol. 67, pp. 1-14, Jun. 2016.

[50] P. Tientrakool, Y.-C. Ho, and N. F. Maxemchuk, "Highway capacity benefits from using Vehicle-to-Vehicle communication and sensors for collision avoidance," in Proc. IEEE Veh. Technol. Conf. (VTC Fall), Sep. 2011, pp. 1-4.

[51] D. J. Fagnant and K. Kockelman, "Preparing a nation for autonomous vehicles: Opportunities, barriers and policy recommendations," Transp. Res. A, Policy Pract., vol. 77, pp. 167-181, Jul. 2015.

[52] C. Gkartzonikas and K. Gkritza, "What have we learned? A review of stated preference and choice studies on autonomous vehicles," Transp. Res. C, Emerg. Technol., vol. 98, pp. 323-337, Jan. 2019.

[53] D. J. Fagnant and K. M. Kockelman, "The travel and environmental implications of shared autonomous vehicles, using agent-based model scenarios," Transp. Res. C, Emerg. Technol., vol. 40, pp. 1-13, Mar. 2014.

[54] Qualtrics. (2020). Predicted Duration. Qualtrics. Accessed: Nov. 2, 2020. [Online]. Available: https://www.qualtrics.com/support/ survey-platform/survey-module/survey-checker/survey-methodologycompliance-best-practices/

[55] R. M. Groves, E. Singer, and A. Corning, "Leverage-saliency theory of survey participation description and an illustration," Public Opinion Quart., vol. 64, no. 3, pp. 299-308, 2000.

[56] H. B. Mann and D. R. Whitney, "On a test of whether one of two random variables is stochastically larger than the other," Ann. Math. Statist., vol. 18, no. 1, pp. 50-60, Mar. 1947.

[57] B. Schoettle and M. Sivak, "Public opinion about self-driving vehicles in China, India, Japan, the U.S., the U.K. and Australia," Transp. Res. Inst., Univ. Michigan, Ann Arbor, Lansing, MI, USA, Tech. Rep., 2014 [Online]. Available: https://deepblue.lib.umich.edu/handle/2027.42/ 109433?show=full

[58] T. Stoiber, I. Schubert, R. Hoerler, and P. Burger, "Will consumers prefer shared and pooled-use autonomous vehicles? A stated choice experiment with swiss households," Transp. Res. D, Transp. Environ., vol. 71, pp. 265-282, Jun. 2019.

[59] H. F. Kaiser, "The varimax criterion for analytic rotation in factor analysis," Psychometrika, vol. 23, no. 3, pp. 187-200, Sep. 1958.

[60] D. M. Blei, A. Y. Ng, and M. I. Jordan, "Latent Dirichlet allocation," J. Mach. Learn. Res., vol. 3, pp. 993-1022, Mar. 2003.

[61] J. D. Mcauliffe and D. M. Blei, "Supervised topic models," in Proc. Adv. Neural Inf. Process. Syst., 2008, pp. 1-8.

[62] W. H. Greene and D. A. Hensher, Modelling Ordered Choices: A Primer, 1st ed. New York, NY, USA: Cambridge Univ. Press, 2010.

[63] B. Mabey. (2014). pyLDAvis. [Online]. Available: https://pyldavis. readthedocs.io/en/latest/index.html

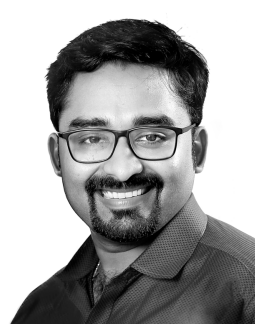

Vishnu Baburajan is currently pursuing the Ph.D. degree in MIT-Portugal program with the Instituto Superior Técnico, Lisbon. He was as a Research Engineer with SMART from 2015 to 2016. He is also a Guest Ph.D. Student with the Technical University of Denmark, Copenhagen. His research interests include trip-based modeling and activity-based travel demand modeling. He was a recipient of the Scholarship from the Fundação para a Ciência e a Tecnologia, Portugal, in 2016. He was also a recipient of the Grant for Short Term Scientific Mission from the COST Action TU1305 of the European Cooperation for Science and Technology. He is a member of the International Association for Travel Behavior Research (IATBR).

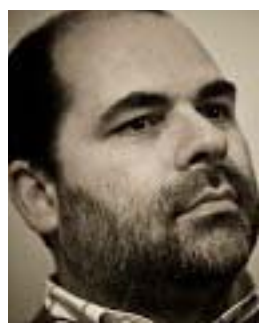

João de Abreu e Silva is currently an Associate Professor with the Instituto Superior Técnico, Lisbon. $\mathrm{He}$ is also a registered Transportation Specialist and a Senior Professional Engineer with the Portuguese Engineers Society. He is a Full Member of the Institute for Civil Engineering Research and Innovation for Sustainability. He has been involved in several research projects in areas related with sustainable urban mobility, transport land use interactions, transport demand modeling, data collection and intelligent transport systems, social networks, transport megaprojects, and equity. He has authored more than 130 international publications. He has also been involved in several international scientific networks, is also a member of three Standing Committees of Transportation Research Board, International Steering Committee for the Transport Survey Conference, a member of IATBR and NECTAR. He is a member of the Editorial Board of Transportation Letters, an Editor of the Journal of Transport and Land Use and the Vice-Chair of the World Society for Transport and Land Use.

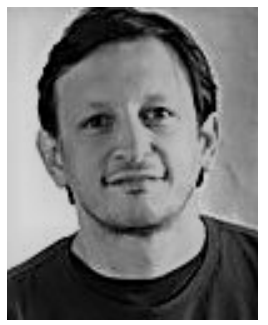

Francisco Camara Pereira (Member, IEEE) is currently a Professor with the Technical University of Denmark (DTU), where he also leads the Machine Learning for Smart Mobility Group (MLSM). His research interests include about the methodological combination of Machine Learning and Transport Research, and some applications include demand modeling, traffic prediction, data collection, or anomaly detection. He is a Marie Curie Fellow and has published more than 50 articles in both machine learning and transport research fields. Before joining DTU, he was a Senior Research Scientist with SMART/MIT from 2011 to 2015 and an Assistant Professor with the University of Coimbra from 2005 to 2015 . 